\title{
1. What is the economics of Uber (and of this book)?
}

What is so special about Uber? Consumers are used to dealing with different companies and brands. They buy vegetables and meat, home appliances and apparel, cars and tools, go to the hairdresser and to a restaurant, take counsel from a lawyer or from an accountant. These are all companies; some of them are even branded. The customer, however, only seldom identifies her person with the company she does business with. Even to brands, devotion is very seldom. Uber, however, seems to be more than just a brand - and being a brand is already something special. Uber seems to have not just customers but a 'fellowship': people identify important actions in their lives with the mobility provided by Uber. For the members of this 'fellowship,' Uber gives special meaning to important actions or parts of their lives. For some, Uber is even a worldview, a weltanschauung. ${ }^{1}$ And if that is already a phenomenon from the sociologist's point of view, from the economist's it is even more overwhelming: Why do people identify themselves with a company to which there are many substitutes? Why do people identify themselves with a company that openly admits monitoring them and surging its prices, whenever its own 'fellowship' gets too attached? Shouldn't this behavior make Uber more exchangeable and not less? Reality shows the opposite to be true.

In addition, Uber is often considered either a phenomenon of its own or a token of the so-called sharing economy. Hailed by some, vilified by others, Uber and the sharing economy established themselves in the lives of many people and in the economies of most countries. And this raises the attention of economists. Can economics describe and analyse Uber or the sharing economy using its current toolbox? Are such fundamental concepts as market, welfare, equilibrium, profit or cost even applicable to the sharing economy? Or are Uber and the sharing economy completely different types of economic endeavor that require a different and new set of theories to be dealt with. Do Uber and the sharing economy revolutionize economics as a science and as a practice?

Uber and the sharing economy pose many important questions even before the start of the case study of this book, which is Uber and the 
relationship between innovation and regulation. And so, here lies an additional problem: in discussing the implication of Uber and the sharing economy on economics, economic concepts are needed in the first place. Examining if and how fundamentally different both are supposed to be from economics depends on the conception of economics being employed. And this is the task of this chapter: to lay out the book's conception of economics and to describe the sharing economy and Uber within it. In addition, the chapter will reference some conceptions that are dismissed in the theoretic approach chosen in this book and how they might lead to a different analysis of Uber and the sharing economy.

In the first section, the chapter develops a framework for analysing the sharing economy and Uber. In the second section, this framework is applied to the sharing economy. In the third, Uber will be the focus; it is this third section that builds a bridge to the next chapter. A short summary answers the chapter's leading question.

\subsection{THE ECONOMIC FRAMEWORK}

The economics of this book relies on two fundamental ideas. The first is that individuals are free to act, which means that they are free to choose between alternative actions but are at the same time responsible for their choices. The second is that the notion of a market is best understood as an open-ended, multi-polar, non-determined series of processes. This conception of economics is typical of the Austrian School in Economics. The meaning of 'Austrian School' as well as the two fundamental ideas that are their base are explained in this section.

\subsubsection{Austrian School in Economics}

The Austrian School in Economics is a heterodox approach to economics. Heterodox means that it is not the mainstream or the majoritarian theory to which most economists subscribe. The Austrian School in Economics is not the only heterodox approach in today's economics. Other are, for example, socialist, Marxian, institutional, evolutionary, land-based (Georgist) or post-Keynesian economics. If these are the heterodox approaches, what is the 'orthodoxy' from which they all deviate? It is the 'neoclassic-Keynesian synthesis.' Blanchard (2008, p. 831) describes the synthesis:

The term 'neoclassical synthesis' appears to have been coined by Paul Samuelson to denote the consensus view of macroeconomics which emerged 
in the mid-1950s in the United States. This synthesis remained the dominant paradigm for another 20 years, in which most of the important contributions, by Hicks, Modigliani, Solow, Tobin and others, fit quite naturally. The synthesis had, however, suffered from the start from schizophrenia in its relation to microeconomics [the synthesis uses Keynesian macroeconomics and neoclassical microeconomics, which generated paradoxes], which eventually led to a serious crisis from which it is only now re-emerging.

Mainstream economics is primarily concerned with the results of markets. It subscribes to the idea that markets, macro and micro, tend toward equilibrium. This means that there is an ideal configuration of price and quantity that clears the market. When this configuration is achieved, the interests of all market agents are optimally fulfilled. This is the case, for example, in full employment, optimal economic growth or perfect competition. If a given economy is not in any of these states, there is room for improvement. Specifically, policies based on economic instruments can be used - some would claim must be used - to reach the equilibrium. And how do economists and regulators know the equilibrium configuration? Well, mainstream economics determines that at least theoretically, equilibria configurations for markets can be determined or calculated, even beforehand, by using market data and analytic tools.

Austrian economics - among other heterodox approaches - disagrees with most of this. Mostly because Austrian economics remains agnostic about the results of markets and directs its attention to their constituent elements. For most Austrian economists, it is the preconditions of market processes that matter. These are individual decision-making processes, innovation, subjective discovery of utility, cost or exchange possibilities as well as forms of cooperative practices. The Austrian School in Economics neither tries to reconcile Keynesianism with the so-called classic, laissez-faire approach nor can it be thought of as a monolithic bloc. Austrian economics is a heterodox way of thinking about economics that is itself full of heterodoxies. Boettke (2008) identifies the following ten main propositions that are common to so-called Austrian economists:

1. Only individuals choose: economics, then, explains how these choices were made on which grounds and which consequences intended and non-intended - they had.

2. The study of the market order is fundamentally about exchange behavior and the institutions within which exchanges take place: economics studies the different series of decisions regarding exchanges and how these institutions are formed.

3. The 'facts' of the social sciences are what people believe and think: 
economics and all social sciences deal with social constructions (see also Searle 1995). ${ }^{2}$

4. Utility and costs are subjective: economics is the study of the utility and costs of alternatives in light of the individual's subjective point of view.

5. The price system economizes on the information that people need to process in making their decisions: economics sees prices as the results of the different choices and exchanges in which individuals engage; individuals use prices as bearers of information about the choices of other individuals, that is why prices are relative in nature and are relative to the individual economic agent.

6. Private property in the means of production is a necessary condition for rational economic calculation: without private property, the individual is not able to reflect all subjective calculations of utilities and costs of choices into the decision to act.

7. The competitive market is a process of entrepreneurial discovery: competition is an open-ended, non-determined process of discovery of innovation, but also of individual discovery of utilities and costs.

8. Money is non-neutral: as money enters the economy, it influences relative prices; since prices are a function of individual utility and cost calculations, money entering the economy impacts each agent differently on each relation of relative price.

9. The capital structure consists of heterogeneous goods that have multi-specific uses that must be aligned: production is always for an uncertain future demand, and the production process requires different stages of investment; the values of all producer goods at every stage of production derive from the value consumers place on the product being produced.

10. Social institutions often are the result of human action, but not of human design: social institutions emerge by the common or cooperative practices of those social agents engaged in exchange; if these agents grow disinterested in one specific social practice, that practice ceases existing altogether; if agents start a new social practice, a new social institution emerges. Agents following other agents in a social practice is the constitutive moment of that institution; not its design.

Boettke (2008) is also clear in stating the result of these propositions:

The implications of these ten propositions are rather radical. If they hold true, economic theory would be grounded in verbal logic and empirical work focused on historical narratives. With regard to public policy, severe doubt would be raised about the ability of government 
officials to intervene optimally within the economic system, let alone to rationally manage the economy.

This list calls for a comment on three peculiarities of Austrian economics. First, these propositions do not mean that all economists belonging to the Austrian School share the same ideas. The ten propositions mentioned here are just a set common to most. And common means something along the lines of Wittgenstein's family resemblance ${ }^{3}$ rather than hard criteria by which every single Austrian economist can be distinguished from a non-Austrian one. Second, very often, Austrian economics is identified with right-wing political ideology. This is wrong. There is no necessary connection between Austrian economics and any partisan politics. While it is true that Austrian economists are generally skeptical of state intervention, there have been different self-identified Austrian economists that accepted it to some degree - Schumpeter being one of them. Also, many policies typically championed by right-wing groups are met with disapproval by the majority of Austrian economists, for example, overarching security policy, international (military) engagement, loose monetary policy (even if it is demanded by private agents in the economy), among others. ${ }^{4}$

The third peculiarity, or even oddity, of Austrian economics is that it cannot be found in Austria anymore. Almost all economists inspired by or self-identified with Austrian economics are today in the United States and Canada, as well as some in small pockets in France, Germany, Switzerland, Liechtenstein and Spain. Austrian economics is called such because it began in the University of Vienna. So, when a given economist is called Austrian, it seldom means that the economist is from Austria. Likewise, the adjective Austrian in this book denotes an economist of this persuasion rather than Austrian nationals. Schumpeter is one exception: he was an Austrian national and an Austrian economist. The 'founder' of the Austrian School was also an Austrian national (and a tutor to the crown-prince to the Habsburg Empire; and a champion for giving the poor access to the economy), Carl Menger (1840-1921). Menger came up with the important principle of Austrian economics: the economic values of goods and services are subjective in nature. Bluntly put: what is valuable for you may not be valuable for your peer. With an increase in the number of goods, their subjective value for an individual diminishes. This valuable insight lies behind the concept of what is called subjective diminishing marginal utility. Subjective is the operative word for 'Austrianism.' 
Some other well-known Austrian-Austrians are Ludwig von Mises (1881-1973) and Friedrich August von Hayek (1899-1982). NonAustrian (nationals) Austrians (economists) are Murray Rothbard (19621995), Israel Kirzner (born 1930) and Lew Rockwell (born 1944). Some Nobel laureates have been inspired by Austrian economics, for example, James Buchanan (1919-2013) and Vernon Smith (born 1927). Also, the other economist and management scholar mentioned in Chapter 3, Clayton Christensen, has been influenced by Austrian economics. So, Austrian economics is not only the theoretical background from which this book is written. It is also the background or the influence that marked those individuals that came up with the theories behind creative destruction and disruptive innovation. Austrian economics, therefore, is also an appropriate way of reading Schumpeter and Christensen because it is close to their own point of view. ${ }^{5}$

This brief overview on the Austrian School serves as a background to the actual understanding of economics in this book. Here, markets are viewed as a series of open-ended, undetermined processes, or series of individual exchanges. While economists of all persuasions could subscribe to this conception of the market to some degree, it matches best with the Austrian approach. What it means to view the market as a series of processes will be discussed in the next subsection. In case of curiosity, more information about the Austrian School can be found in Grassl and Smith (1986), Boettke (1994) or Schulak and Unterköfler (2011).

\subsubsection{Markets as Processes}

A characteristic feature of the Austrian approach to economic theory is its emphasis on the market as a process, rather than as a configuration of prices, qualities, and quantities that are consistent with each other in that they produce a market equilibrium situation. This feature of Austrian economics is closely bound up with dissatisfaction with the general use made of the concept of perfect competition. It is interesting to note that economists of sharply differing persuasions within the Austrian tradition all display a characteristic disenchantment with the orthodox emphasis on both equilibrium and perfect competition ... From the Austrian perspective, which emphasizes the role of knowledge and expectations, these explanations take too much for granted. What is needed is a theory of the market process that takes explicit notice of the way in which systematic changes in the information and expectations upon which market participants act lead them in the direction of the postulated equilibrium 'solution.' (Israel Kirzner 1976, 3.1.1 and 3.1.8)

Understanding the market as a series of processes entails giving up the idea of a calculable, predetermined equilibrium. It also means that markets cannot be judged by their results because there are no results, 
just stages of the processes. This position makes economists focus instead on the different series of discoveries that agents go through when they engage in voluntary exchange. In this view, markets are open-ended, undetermined processes for satisfying the individual's subjective needs. Of course, these individual needs can change too. They change as a function of the subjective satisfaction or dissatisfaction individuals might have, but they also change according to the individual's context, learning processes and even moods. In the continuous interactions with other people, individuals not only learn but constantly reveal information about their own preferences and decisions. The market as such is just a linguistic marker denoting a series of multi-agent, multi-layered, multilateral learning processes.

Therefore, the descriptive term market is understood here as just an abbreviation for (or even a metaphor denoting) a whole conglomerate of processes, interactions and exchanges between individual entities that engage therein freely and without ex ante central coordination. The market is a dynamic place to gather and reveal information; as such, it is a dynamic place to learn. Markets consist of the continuous revelation of individual and collective preferences, means-ends calculations, assessments (of the self and the others) and information stocks by its agents; they are choosing individual entities, like the individual or the voluntary group. The outcomes of markets, prices and quantities are but aggregate information about these individual and subjective revealed preferences. The outcomes of market processes have no other quality than being aggregate bearers of information (Kirzner 1996; Schneider 2014). These outcomes cannot be understood in terms of 'good' or 'bad' or even 'ideal,' since they are only 'good,' 'bad' and 'ideal' from the subjective perspective of each agent. If market processes produce what seems to be a distortion or if the results of markets are difficult for economists to explain, in this approach, economists will go back to the study of the general conditions under which market processes unfold themselves. They will ask, for example, which factors influenced decisions, which information flows were available to the agents, how aligned individual choices and the bearing of their consequences were and so on. In this approach, if market processes seem to be generating problematic outcomes, it is analysed whether there is anything in these general conditions preventing individual agents from gathering information, assessing information, making own and subjective decisions and so on. If nothing distorting these preconditions for market processes is found, then all outcomes are to be accepted. Often, this approach will reveal that state agent interventions distort or at least skew the preconditions for the market processes to unfold. 
What would be the alternative view of the market? As mentioned earlier, mainstream economics has a different conception. Often, the market is pictured as an institution, that is, a central area of exchange with rules, agents, oversight and a whole array of very real entities and properties (Ross 2014). This institutional conception of the markets shares many aspects with the Austrian idea: both see individual decisionmaking as pivotal, both pay close attention to the flows of information and to the learning of market agents, both see the market as a plug-andplay situation. However, the differences between both concepts are also important.

One important difference is the mainstream idea that all markets strive for equilibrium. That does not mean that a market-clearing configuration will automatically be reached, but there is always at least one potential optimal situation for every market and this situation can be reached primarily by the market agents through their interactions, secondarily by regulation. Seeing the market as a closed-case institution automatically means assigning a regulatory entity to that institution. While the Austrian approach sees the rules of an institution or of a process as emerging from the cooperative social practice that leads to that institution or process, the mainstream approach sees markets as an initially designed institution. Designed by whom? By the regulator; mostly by the state (Ross 2014).

This difference deserves more emphasis because it is crucial: the institutional understanding of markets believes that there can be no markets without regulations and regulators - they are constitutive of the market. This does not entail that the regulation must necessarily be one by an entity with power over the agents, like the modern-day nation-state. Market agents themselves can come up with the regulation of their market institution. But many contemporary orthodox economists claim that regulation by the nation-state is more effective and more efficient than the self-regulation of market agents (Ross 2014). Why do Austrians oppose this view? Because this institutional view implies that there are hard-fact results of markets and that regulators can anticipate these results. The second implicit assumption is that regulation makes it easier for the market to achieve its predetermined results (or those results that lead to a maximization of welfare; see further below). Most importantly, the third assumption of this view is that the results of markets can be judged objectively. As mentioned before, Austrian economics sees the market more as a way of communication than as a mechanism for reaching a given social goal. Since the results of the market processes underlie open-ended, undetermined dynamics and these results can only be judged individually, it would be overbearing to claim that the market has a teleological goal and that some agent, the regulator, has some 
epistemic advantage over others and can ultimately decide between the 'good' and the 'bad.'

There is yet another important difference between the institutional view of the markets and the process approach. This institutional view strongly suggests that these regulations, in order to work, cannot and should not be influenced or legally circumvented by individuals. This is the case because markets are not only a place of exchange but also an instrument to promote social welfare. So, regulators use markets in order to promote social welfare. Skeptically, it could be asked now how all the elements - individual responsibility, free-willed exchange, predetermined outcome and the promotion of social welfare - fit together in this institutional view.

Here it gets tricky: promoting social welfare, according to this institutional view of markets is not completely incompatible with individuals' decisions and learning processes. The idea of equilibria comes in handy now. As mentioned before, if a given market reached its configuration of equilibrium, agents are all optimally served. In most points of equilibria, all of the participants of the market have reached their best possible welfare. So, it is the regulator's job to create the best possible conditions for markets to find their optimum states (Ross 2014). But mainstream economics can go even further in the quest for welfare maximization. 'An allocation of resources is Pareto efficient if it is not possible (through further reallocations) to make one person better off without making someone else worse off' (Reetz 2005, p. 26). This sentence is the definition of Pareto efficiency. And upon this idea many postulates of welfare maximization are grounded. Note that the Pareto maxim is about efficiency and not about desirability and note too that it is about the allocation of resources. Welfare economics turns it into the allocation of outcomes and interprets the maxim like this: 'If it is possible to reallocate outcomes in order to make a person better off without making someone else worse off, this reallocation should be pursued' (Reetz 2005, p. 108). With this reformulated Pareto maxim, not only the goal of regulation is stated but also a task is given to the regulator; it has to intervene in the market until the social optimal outcome allocation is achieved.

Here again the Austrian approach disagrees. As mentioned earlier, this institutional theory of markets has a number of flaws: as profoundly dynamic processes, markets have no pre-set equilibrium point, and even if they had, it would be impossible to know them beforehand, or even as they occur, since equilibria constantly change with the dynamic of the process. A third party, for example, the regulator, cannot know more than the information being exchanged in the markets since market agents are 
at the same time members of the regulatory body (yes, if someone looks into a market, this person becomes an agent). More plainly put: regulators are subjective individuals like those people participating in the market process; they cannot know more about the future than anyone else. If there is no pre-set, optimal equilibrium, the welfare maximization postulate becomes obsolete, since it is necessarily dependent on equilibrium. ${ }^{6}$ Also, the welfare maximization postulate presupposes that there is an objective measure for categorizing the output of markets. But from the market process view, there is not. How desirable the outcome of a market process is depends on the subjective value judgement on each market agent. If one market agent is not happy with the outcomes, this person will engage in other exchanges and try to influence the outcome in light of individual preferences. So, if markets are understood as processes, welfare is the individual's or the voluntary group's concern. Through freely deciding, acting and learning, agents will deal with what they individually consider to be their welfare.

The consequences of subscribing to this process-based conception of the market become apparent now. The most important consequence of understanding the market as a form of spontaneous exchange is that there is no optimum, end-state or result that can be assessed a priori, or even before the exchanges occur. This means that no market agent or regulator is in the position of knowing the outcomes of the process of spontaneous exchange since no one knows how individuals or groups of individuals will behave, react, learn, adjust, strategize, change their preferences, think, cooperate, evaluate or even withdraw among other things. The complexity of the free-willed spontaneous exchange rules out the possibility of ex ante knowledge about its outcomes. In taking this view, one has to admit that there is no guarantee for innovation being successful or failing, since it is a series of complex processes with multiple possible and interdependent outcomes that will ultimately establish if, how long and under which circumstances a given innovation succeeds and/or fails. In this view, so-called consumer protection is something best done by the individual consumer acting responsibly. Or the individual consumer can organize other individuals into a group and this group could engage in a series of exchanges with one or different suppliers. While this process understanding of the market allows for agents to have individual expectations or desiderata relating the outcomes of markets, they cannot have actual, factual knowledge about it.

What justifies regarding the market as a series of processes? There are two main arguments. The first is logical consistency. If individuals or groups of individuals decide freely what to do, the outcomes of these decisions and their interdependencies are too complex to be known 
beforehand. Before the internet, there was no knowledge of the outcomes of the internet. Before Uber, there was no knowledge of its outcomes. Even as it started, there was no knowledge of how it would develop and which impacts it would have. The second argument is what often is called Ockham's razor, ${ }^{7}$ which can be stated as follows: among competing explanations, the one with the fewest assumptions should be selected (see Ariew 1976). This principle is about the burden of proof. The explanation that claims more has to prove more. Therefore, if the institutional view on markets presupposes an optimum, or equilibrium, it is that view's task to demonstrate that there is one. And that is a difficult thing to prove. On the other hand, in claiming that the market is just a series of exchanges, there is less to prove about it. For example, if someone claims that the outcomes of market interactions can be known, the burden of proof dictates that it has to be proven how the outcomes can be known. Sticking to the simpler understanding of the market as the spontaneous exchange of individuals and groups of individuals is more consistent with the razor.

With these explanations given, it becomes easier to understand why this book follows the Austrian approach and conceptualizes markets as processes. First, creative destruction and disruptive innovation were developed by authors that subscribed to the Austrian School at large or were influenced by it. Therefore, it seems fair to discuss their ideas from the perspective in which they are founded or by which they were influenced. Creative destruction and disruptive innovation are not just metaphorical terms or buzzwords; they are, at least, part of economic theories.

Second, even proponents of the institutional view of markets don't deny that regulating markets is a difficult endeavor since no one willingly wants to bring all innovation to a halt. Even regulation cannot be pursued maximally, just, in their view, to a configuration in which it trades off gains from regulation and regulation-induced costs (for example, its negative impact on innovation). So, even these proponents study the positive and negative effects of regulation on markets and their agents. In order to determine the equilibrium point of regulation, regulation has to try to understand the market it is trying to regulate (Armstrong 1999). Therefore, also from the institutional point of view, an analysis of the dynamics in a given market is desirable.

Using the conception of markets as a series of processes in this book means we don't know what the future of the ideal transportation market is. Taxicab companies do not know it; Uber does not know it; regulators do not know it; customers do not know it and especially this author does not know it. The analysis of Uber's activities, regulation and innovation 
occurs then in terms of the open-ended, non-determinate dynamic of markets understood as learning processes (and not in terms of supposed equilibria of markets).

\subsubsection{Individual Action}

Another aspect of the methodology being employed here is that individual action is at the center of attention. It is the individual or the voluntary group of individuals that make decisions about what they want, how to pursue what they want and how to live with the outcomes of their actions. As discussed above, contrary to most other approaches in economics, the Austrian School is not primarily concerned with market institutions, social welfare, money and such, but with actions, adaptations, responsibility, information (beliefs) by the individual or by a voluntary group of individuals and how factors impact on these agents, distorting their decision-making. As long as the preconditions for engaging in the market process - for example, monetary stability, symmetry of risk and responsibility, freedom of choice - are aligned, individuals or voluntary groups will be able to do what they consider best. As soon as these preconditions are distorted, however, individuals and voluntary groups will engage in a downward spiral of maladjustments to the distortions (Kirzner 1996; Mises 1927, 1933). The reason is that the agents in the markets adapt their decision-making to the very factors distorting them. Their individual and subjective calculation of beliefs, preferences and costs starts to encompass elements of which they might profit or by which they might be disadvantaged without having any possibility of either influencing those elements or taking responsibility for them. Distortions, however, have to be separated from possible states of the market process that might be considered undesirable from a subjective perspective. Distortions of the market processes occur when an agent outside the market dictates terms to the processes or agents of the market. When market agents try to dictate terms to one another, they can through the market processes react to it; they cannot, however, react to the agent that dictates its terms to the markets from outside the process. For example, people have no market influence over telephone regulations. But if a single telephone company tries to dictate terms to the users, they just switch to another. The market process disciplines the actions of its agents, that is why even an agent with strong power over a given point of the market process is held in check by the process. State intervention and the like exert power over the market process without the market process being able to discipline the source of power. This is a distortion. 
Individuals act and react in market processes based on their own calculations of utility and costs. Innovation and the whole of entrepreneurship are, therefore, the result of or constitute a series of decisions taken by an individual or a voluntary group of individuals. To the contrary, regulation is seen as rules of behavior dictated to individuals or voluntary groups of individuals. Regulation is not ground in the freewilled decisions of the agents. Often, regulation prevents individuals from becoming innovators or entrepreneurs, since both are not only a combination of technical skills, but constituted by what one might call 'taking advantage of the moment.' The more regulation constrains the actions of individuals, the more difficult it becomes to take this advantage. Kirzner (1976, 3.1.14) establishes the link of individual, entrepreneurship and process:

Misesian theory of human action conceives of the individual as having his eyes and ears open to opportunities that are 'just around the corner.' He is alert, waiting, continually receptive to something that may turn up. And when the prevailing price does not clear the market, market participants realize they should revise their estimates of prices bid or asked in order to avoid repeated disappointment. This alertness is the entrepreneurial element in human action ... At the same time that it transforms allocative decision making into a realistic view of human action, entrepreneurship converts the theory of market equilibrium into a theory of market process.

Of course, regulation could be accepted if it is incurred voluntarily, since then it is one of those decisions taken by individuals. But by the same standard, individuals should be able to opt out of regulations. In this dynamic view, rules would emerge from human action as a certain type of cooperative practice. And since rules are confronted with the steady pressure of human action, they adapt to the needs of the individuals, becoming processes too. Judging how regulation and the individual interact depends on the responses to the following questions: how much influence do individuals have on the regulation, and what can they do if they don't agree with it?

As for the first: if regulations are the direct fruits of decisions by individuals, as they are, for example, among condo owners or by shareholders in businesses, they are not distortions of the preconditions of markets as explained above. These regulations have been incurred voluntarily by the individual and this individual retains the right of opting out, for example, by selling the flat or the shares. Most importantly, as co-owner, the individual has an important role to play in steering this set of rules. Note that, different from political influence, here the individual 
has a direct influence in the company's strategy or the condo's policies. The individual acts directly and unconditionally upon his co-propriety.

As for the second: even if there are rules upon which the single individual has no direct influence (that is, what economists call exogenous), if the individual can walk away, there is less of a problem with that set of rules. In this case, the rules themselves are submitted to competition and the individual still has the possibility to freely choose what to do. This might be the case in the labor market (if I am not happy with the rules of my employer, I change my job) or with sports clubs (if I don't like the by-laws of my gym, I look for a new one), for example. Note that the individual here has no direct power over the regulation, since employees don't own their employer and customers don't own their suppliers, but by the voluntary actions of employees and customers, the respective sets of rules are under pressure.

The distortion of the individual's liberty to decide and to act begins there, where regulations are dictated to individuals without giving them a say or the opportunity to decide otherwise. For example, before the market entry of Uber, if I wanted to get a cab in New York City I could not change the cab regulation, say, to choose which type of car I want or how to reduce the asymmetry of information concerning the driver's credentials. I basically had to take the cab that the regulation assigned to be driving. Also, I could not take any other type of cab, just the regulated ones. Similar constraints apply if I want to start a taxicab business. I have to adhere to the regulation upon which I have neither influence - at least not as a small- or medium-sized company - nor the possibility to circumvent (legally, of course). There is a distortion of the individual's liberty to decide and act here, because the individual basically cannot decide on what to do, but to comply with exogenous impositions on her behavior. The downward spiral might be that the person starting a taxicab company, despite the initial plan to offer flexible rates or better service, will only offer the regulated industry standard.

To sum up this subsection, while the Austrian School in Economics is the general background for this book's analysis of Uber, the conception of the market as processes is its most important tool. Markets are open-ended, indeterminate series of exchanges by individuals. So, the individual is the pivotal entity. Innovation is the possible consequence of the individual's or the voluntary group's decisions in entrepreneurship. Innovation, however, is no guarantee for success. Success is at best a subjective value judgement about a temporal outcome of the market process. The so-called innovators will learn from their own success and/or failure and adapt their actions and decisions to what they have learned. 


\subsection{SHARING ECONOMY AND ITS NOVELTY}

Now it is time to apply the frame of reference developed above to two subjects: to the sharing economy and to Uber. First, let the sharing economy be considered. What is it? What is new about it? And is there anything essentially different to the sharing economy?

\subsubsection{Sharing, Collaborative or Cooperative?}

There are many different ways of defining the sharing economy. For starters, there is no single definition. What some call the sharing economy is called by others the collaborative economy or the cooperative economy. But then again, some claim that these expressions denote different phenomena. Keeping in mind that there is a market for definitions, one should not expect one single, all-embracing definition to establish itself. Also keeping in mind that the market is a learning process, one should expect definitions to change as new business models emerge. Rachel Botsman (2015), one of the best-known analysts of the sharing economy, offers an explanation for the diversity of definitions an explanation not without irony:

The 'sharing economy' is a term frequently incorrectly applied to ideas where there is an efficient model of matching supply with demand, but zero sharing and collaboration involved. Platforms such as Washio, Deskbeers, Dashdoor, and WunWun that require the tap of an app to instantly access a clean shirt, massage, or keg of beer are fundamentally different from platforms like BlaBlaCar or RelayRides, which are genuinely built on the sharing of underused assets. Pizza Hut and Amazon one-hour delivery aren't the sharing economy, and these on-demand apps are no different; they are mobile-driven versions of point-to-point delivery. They're thrown under the same umbrella as part of the sea change in consumer behavior that uses the smartphone as a remote control to efficiently access things in the real world. This muddiness in terminology is partly coming from Uber. The experience of using geolocation and frictionless payments to change our ability to get a taxi is creating a transformation in terms of how we expect and want to access everything from getting a parcel shipped on Shyp to a dog walked on Wag, with a tap of a screen. But the Uberfication of everything brings with it confusion about what is true sharing.

Not every digital platform is automatically part of the sharing economy. While in today's manifestation, the sharing economy heavily relies on technology, especially the internet, it is not by necessity so. Inversely, not every business or not-for-profit organization with a web presence is engaging in the sharing economy. Botsman (2015) and Botsman and 
Rogers (2010) offer five criteria for delineating what it means for a business to be in the sharing economy:

1. The core business idea involves unlocking the value of unused or underutilized assets ('idling capacity') whether it's for monetary or non-monetary benefits.

2. The company should have a clear values-driven mission and be built on meaningful principles including transparency, humanness and authenticity that inform short- and long-term strategic decisions.

3. The providers on the supply side should be valued, respected and empowered and the companies committed to making the lives of these providers economically and socially better.

4. The customers on the demand side of the platforms should benefit from the ability to get goods and services in more efficient ways that means they pay for access instead of ownership.

5. The business should be built on distributed marketplaces or decentralized networks that create a sense of belonging, collective accountability and mutual benefit through the community they build.

Based on these criteria, Botsman (2015) gives a finer-grained set of definitions of the different aspects of what is commonly referred to as the sharing economy:

Collaborative Economy: An economic system of decentralized networks and marketplaces that unlocks the value of underused assets by matching needs and haves, in ways that bypass traditional middlemen. Good examples: Etsy, Kickstarter, Vandebron, LendingClub, Quirky, Transferwise, Taskrabbit

Sharing Economy: An economic system based on sharing underused assets or services, for free or for a fee, directly from individuals. Good examples: Airbnb, Cohealo, BlaBlaCar, JustPark, Skillshare, RelayRides, Landshare

Collaborative Consumption: The reinvention of traditional market behaviors renting, lending, swapping, sharing, bartering, gifting - through technology, taking place in ways and on a scale not possible before the internet. Good examples: Zopa, Zipcar, Yerdle, Getable, ThredUp, Freecycle, eBay

On-Demand Services: Platforms that directly match customer needs with providers to immediately deliver goods and services. Good examples: Instacart, Uber, Washio, Shuttlecook, DeskBeers, WunWun

One might disagree with Botsman's categorization. For example, does Uber not involve sharing the car that incidentally often belongs to the 
driver? But even if there is no complete agreement with Botsman, these criteria and definitions provide a good perspective into the diversity of economic activities or processes that can be understood by the sharing economy. But what drives them? Researchers usually distinguish three different types of drivers in the sharing economy: economic, technological and societal. Economic drivers are: monetization of excess or idle inventory and capacity; increase in financial flexibility; preference for access over ownership; and influx of venture capitalist funding. Technological drivers are: social networking; mobile and devices platform; and e- or online payment systems. There seems to be less consensus about the societal drivers of the sharing economy. Some researchers tend to use the following, or at least some of them: increasing population density; drive for sustainability; desire for community; and generational altruism (Botsman and Rogers 2010; Chase 2015).

But there are not only drivers to the sharing economy, there are also opposing forces. Chase (2015) identifies the following: government officials oppose sharing that disrupts existing regulations; lack of trust between peer-to-peer buyers and sellers; lack of industry-wide reputation systems and data standards; incumbent players view sharing as a threat to their current business models; and uncertainty about which startups will stand the test of time. Note that the last two forces of opposition seem to assume that incumbent companies cannot engage in the sharing economy and only startups can. This assumption is at least theoretically disputable. Equally debatable is the insinuated necessary link between startups and the sharing economy. But from the overall economic perspective, there is an even more pressing question: is there anything radically new in the sharing economy?

\subsubsection{Not So Novel}

Judging if the sharing economy is radically new depends on the standard for comparison. Is it new in comparison to regulated, institutional markets? Or are the learning processes of the sharing economy new? Are the results of the sharing economy new? If so, what is the basis for such a comparison? Are these results, as they are known today, being compared to the results of the traditional economy, as they are known today? Or are the drivers of the sharing economy being compared to the drivers of the traditional economy? This last question may prove the best entry point for a comparison.

The drivers mentioned in the last subsection do not seem novel altogether. Monetization of excess capacity and inventory? After all, communities of people have shared the use of assets for thousands of 
years; for example, roads, ships, planes and restaurants. The person travelling in the plane does not own the plane. It is the airline that decided to acquire capacity and share; that means sell its excess. People eating in a restaurant share the space with other guests and, more importantly, with the owner of the restaurant. And even the business model of hotels began as restaurants decided to rent - share - free rooms. What might have intensified is that the scale and scope of the internet has made it easier for asset owners and those seeking to use those assets to find each other. This, however, is not a revolution of the traditional economy. It is just the enlargement of its agents and processes.

What about the increase in financial flexibility and higher influx of venture capitalist funding? Financial flexibility depends on the subjective preferences of agents. In the development of modern economies, financial flexibility has seen continuous expansions - albeit sometimes curbed by regulation. It is only logical that the more flexible individuals are to use their finances, the more opportunities to invest they will seek. For example, it was the increased financial flexibility and the intention of shared entrepreneurship that made investors create the first limited participation company and call their owners 'shareholders.' The investors share an investment and become owners. With even more financial flexibility, the principle of shared ownership was then expanded to public participation corporations (Hansmann and Kraakman 2000). ${ }^{8}$ Even such phenomena profoundly identified with the sharing economy as crowdfunding have existed before. For example, in the guilds in China (Morse 1909) and Europe (Epstein and Prak 2008) as well as among small- and medium-sized enterprises in North America and German-speaking Europe (Winker 1996), it was usual for businesses to lend money to each other, even forming financial vehicles that resemble investment funds. With respect to finance, the sharing economy does not revolutionize. To the contrary, it expands instruments that have been known and practiced for a long time.

Preference for access over ownership? This is also a very established driver. Many people rent flats and cars. The reason is that they either do not have enough means to buy the asset, or the asset is needed only for a short term or that they just prefer to use the asset and not to maintain it. In any case, access over ownership is a common preference in many societies. Columbus leased the ships he travelled in as much as most people choose to pay for access to a taxicab and not for its ownership. Indeed, economic interaction often presupposes second- and third-party ownership. If I want to buy an apple, I don't want to own a supermarket. I presuppose ownership of a supermarket by a person often unknown to me in order to be able to access the apple I want to buy. Preference for 
access is an arrived idea in economics. What might be happening with the 'sharing economy' is that accessibility is being broadened to more goods, for example, eating in other people's homes (instead of restaurants), sleeping in other people's beds (instead of in hotels, hostels and bed and breakfasts - which were themselves at the forefront of the sharing economy), using other people's infrastructure (for example, cars, trucks, inventory) and so on. But all these examples and counterexamples show that it is not a question of novelty, but one of scale.

On the other hand, technological drivers might have pushed the economic aspects of the sharing economy to another level. The technological drivers identified above were: social networking; mobile and devices platform; and e- or online payment systems. The question of their novelty has at least two aspects. First, are they technological innovations? Here, the answer should be yes. But the second question is whether these technological innovations changed the economics behind the economic drivers mentioned above. And to this second question the answer might be no. The economics of selling unused or underused capacity did not change; neither did the idea of sharing risks, endeavors and responsibility. But it became much easier to offer these opportunities for entrepreneurial actions as it became much easier to scale the opportunities to cooperate, to learn and to access enterprises and entrepreneurs. So, it is not the economics that changed with the sharing economy, but it is technological innovation that gave speed and scale to the dispersion of typically economic ways for individuals and groups to pursue their subjective preferences, to minimize their subjective costs and to learn from themselves and from others in the market process.

It has been mentioned before that there is not so much consensus about the societal drivers of the sharing economy. Or even, there is no consensus whether there are any societal drivers at all. Increasing population density, drive for sustainability, desire for community, and generational altruism were mentioned as some elements that analysts might consider. It is very difficult to assess whether a drive for sustainability; desire for community; and generational altruism really exist. The reason is that contrary to population density, these three are extremely difficult to identify and even more difficult to conceptualize or measure. Population density can explain why there is optimization in the use of resources: if the buying price is lower than the cost of maintaining a resource, it makes sense to buy it. If population density raises the cost of maintenance, the more density increases, the more individuals will generally prefer to pay for access rather than ownership. This reaction to population density often also increases the efficiency of how resources are employed. But there is no logical bridge (let alone a rule) from here 
to admitting that the 'sharing economy' leads to a more sustainable way of life or that sustainability drives the sharing economy. Some individuals might be incentivized to travel more because of Airbnb or Uber; others might be incentivized to cook or eat more because of Mixxta (Share a table) and the like. Similar problems of identification also apply to the so-called longing for community or in intergenerational solidarity, if they even exist. There is no logical connection between them and the sharing economy. But examples in which the sharing economy could be contrary to these supposed drivers are abundant (Hamaria et al. 2015; Möhlmann 2015).

There is, however, a different way of assessing the role of societal drivers in the sharing economy. The individual or the groups involved in the sharing economy have different subjective preferences, including preferences for values. Some will hold sustainability, solidarity and community as important goals in their lives, and they might employ different instruments facilitated by the sharing economy to fulfill their goals. Maybe even it is easier for these individuals and groups to fulfill their goals of sustainability, solidarity and community in the sharing economy - but this has still to be shown. But here, the cause and effect are the opposite from the claim that sustainability and solidarity drive the sharing economy. It is the sharing economy that makes it easier for some people to pursue solidarity and a sustainable lifestyle. As it is the sharing economy that makes it cheaper for those wanting to experience more, travel more and consume more. Unsurprisingly, this is commensurate with traditional economics. It is not the market processes that tell individuals what to do. The market processes enable and facilitate individuals to pursue their own goals.

\subsubsection{Essentialism and Pragmatism}

Is the sharing economy something novel or not? Those that answer 'yes' often have the tendency to combine their perception of the novelty of the sharing economy with some essentialist claim about it. One example of such a claim would be: the sharing economy is something completely new that revolutionizes the way people act in the markets. Markets fail most of the time. People do not accept these market failures anymore. That is why they turn to more equitable relations with each other. The sharing economy is a reaction to market failures.

This argument can be countered by the second example of a noveltycum-essentialist claim: the sharing economy is something new that revolutionizes the exposure of people to power. It breaks the power of regulation and gives back power to the individuals in the markets. By 
engaging in largely unregulated market processes, people escape the grip of regulation, but also constantly challenge any other convergence of power that might arise in the market. The sharing economy is about making the economy more democratic by the unhindered application of market principles to every human action.

Essentialist claims - either the one or the other - are always problematic because they assume several necessary conditions. As it is not necessarily so that markets fail, it is not necessarily so that market agents always disprove of market power. It is not necessarily so that individuals dislike all types of markets, and it is not necessarily so that people, in order to have individual power over relations, turn to markets. Besides these claims of necessity, some of the implications of the two examples are simply contradictory. If markets fail, why do people turn to a form of the market called the sharing economy? What is there that prevents this market from also failing? And with relation to the second claim, if people do not want market power, why did Uber emerge with such a massive power in the market processes?

Much more in line with the understanding of economics outlined in the first section is denying the novelty of the sharing economy. Its economics is the same as the economics of all other series of exchanges. What is different about it is accelerated pace, diminished costs of operationalization and easier learning effects through technology. If conceptualized in such a way, the sharing economy is nothing more - but also nothing less - than a pragmatic arrangement of individuals or groups to a changed or improved technological environment. As a pragmatic arrangement, the sharing economy is in constant flux about which business models it entails, about their results and about its further development. After all, the sharing economy consists of many different series of exchanges in open-ended, undetermined market processes. Those individuals that first combined their business models with the new opportunities created by technology were not meaning to change the foundation of economic exchange. To the contrary, they were taking advantage of a moment. And the advantage they wanted to take presupposes market processes and their economic foundations.

\subsection{THE CASE OF UBER: IS UBER PART OF THE SHARING ECONOMY?}

It is now time to focus on Uber. As any entrepreneur would do, the individuals behind Uber seized an opportunity by engaging in a series of market exchanges. Some of these exchanges were about mobilizing 
financing of the enterprise; others were about organizing technology and expertise. Similarly, Uber acted in the market processes of acquiring labor, customers and suppliers and so on. So far, from the economics behind Uber nothing more special than the action of individual agents in the market processes stands out. The one special element of Uber, at least as it began, was the conscious decision not to buy any cars, but to look for partners with their cars and bring their idle capacity into a network. This is what may be called the differentiator in Uber's idea. While from a managerial and business point of view this is a good idea because it diminishes the amount of assets and the costs related to their maintenance and amortization (and cuts labor costs too), from a purely economic point of view, there is nothing revolutionary about it. This means this business model does not change the economics at all. In fact, it further shows that the Misesian idea of entrepreneurs seizing an opportunity is a good fit to describe these actions.

Connecting partners who at their own risk and with their own assets become part of a network is a 'good' idea since it tends to diminish the costs for all involved, including consumers, and raises opportunities and gains for all, including for the partners. Similar ideas have been applied before Uber, for example, many 'shop in shop' or 'rack jobber' concepts in retail or contract manufacturing. ${ }^{9}$ This does not diminish in any way Uber's entrepreneurship. But at the same time puts it into perspective. So, Uber and its founders acted pretty much as the usual agents in the market processes, trying to seize opportunities, acting according to their beliefs, preferences and costs. Uber does not know if it will emerge successfully in the processes it takes part in; also, its financiers, employees and partners do not know any outcomes before they happen. But these individuals' subjective calculations made them join together on a journey of cooperative practices. Simply put, this is the economics of Uber.

Then, there is a question about Uber's relationship to the sharing economy. Some think of Uber as the most important example of the sharing economy. But, as seen above, there is nothing in the sharing economy that sets it fundamentally apart from other ways of exchanging in the market processes. In this case, Uber is not an archetype for anything. It is just a successful company. Others do not consider Uber a part of the sharing economy at all. Let's assume, for the sake of argument, that there is anything defining the sharing economy: why shouldn't Uber belong to it? One argument that is often offered is that Uber makes profits. First, Uber aims at making profit but so far has not reported any (see Chapter 2). Second, most definitions of the sharing economy accept that its agents might seek profits - Botsman (2015) 
certainly does. Third, and this is the main problem, this argument would not accept any company, probably no one as an agent in the sharing economy, since sharing epistemically presupposes some sort of gain. People only share if they have a preference for it and any preference involves expected utility and gain - albeit not necessarily a monetary gain.

But there is a more sophisticated argument against counting Uber as an agent in the sharing economy. If driver Farook is travelling from Hayward to Sausalito and offers the remaining three seats in his car, he is sharing. If driver Maria waits for people to tell her where to drive to, she is not sharing. But this argument, too, has fallacies. First, it is overly strict with the term 'share.' Share might denote the act of sharing a ride or the fact of sharing an asset, in this case a car. The word sharing is open to both; there are no inherent criteria in its semantics to understand it, only in a limited way of sharing a ride. Second, this argument might work - but it does not - for sorting Uber out of the sharing economy, but does not do justice to others, such as Airbnb, for example. Does the overly strict share argument imply that Gezim has to stay in his apartment if he wants to offer a room to a stranger? Also, Gezim might only incur very small marginal costs by having Fatima staying with him. Does that definition of sharing mean that he is not supposed to charge Fatima more than the marginal costs?

In any case, trying to portray Uber as something potentially outside the sharing economy leads to overly ambitious claims about what the sharing economy is supposed to be - or even allowed to be. No definition about dynamic human actions has this kind of epistemic and binding power. But then again, this discussion offers further plausibility for the view championed in this book. There is no overarching economic phenomenon called the sharing economy. There are business models that rely on networking and selling - or auctioning - idle capacity to customers. These models rely on the market processes, and they especially rely on a higher-paced, learning-intensive market process, that has been facilitated by technology. Uber is a good case for that.

This case merits a deeper appreciation. The next chapter provides an overview on Uber's business model and the entrepreneurship that underlies it. As such, while this chapter provides background to the thinking of this book, the next chapter builds the base for treating Uber as a case study in creative destruction and disruptive innovation. 


\section{SUMMARY}

The chapter provides the background on the economics of this book, on the 'sharing economy' and how Uber can be assessed as an economic agent. This book understands markets as open-ended undetermined series of exchanges between a potentially unlimited number of agents. These agents engage voluntarily in the different market processes without knowing more than the other agents but judging their own beliefs, preferences and costs subjectively. Agents use the market processes in order to learn about other agents' beliefs, preferences and costs. Market processes are cooperative actions.

Whatever might be labelled the sharing economy relies on these market processes and does not in any way fundamentally change them. The sharing economy is not different from the traditional economy; to the contrary, it applies and broadens the application of market processes and individual actions. However, the role that technology plays is important. With the development of online networking, e- and online payment methods as well as individual online mobility, many business models gain scale and scope. Technology often makes it possible to diminish costs of participating in a market process, to learn quickly or gather information in a timely manner as well as to scale up some market processes. Uber, in due entrepreneurial spirit, seized this opportunity and turned it into a successful business model.

\section{NOTES}

1. Weltanschauung is the exact German word for worldview. However, it is often used in English with a philosophical content. It refers to the frame of reference of the subject; the ideas and beliefs upon which a person watches and interprets the world with which he interacts.

2. In his book The Construction of Social Reality (Searle 1995) and later works, John Searle discusses the problem that 'there are portions of the real world, objective facts in the world, that are only facts by human agreement' (p. 42). He describes these objective facts as observer relative features of reality, or components of 'social reality,' as opposed to the intrinsic features of physical reality or 'brute facts,' such as rocks, water and trees. He then asks the question, 'how is a socially constructed reality possible?' and devotes much of this book to providing some answers. According to him, most social entities emerge from cooperative practices, especially cooperative linguistic practices.

3. The philosopher Ludwig Wittgenstein (1889-1951) coined this term. It denotes similar things that are connected not through any one essential common feature, but by many or a series of overlapping similarities. Wittgenstein's paradigmatic example was the one of games: soccer, darts, Warcraft do not share one and only essential and necessary criterion, but they are all called games. They are common social practices that are best referred to as games, even if a player of Warcraft never watched or heard of soccer before. The idea of 
family resemblance is present in much of Wittgenstein's work, but the most detailed explanation is found in his Philosophische Untersuchungen [Philosophical Investigations] (1945).

4. Think, for example, of the financial markets and the Fed's interest rates. Most agents in the financial markets do not want an interest rate hike. These agents are part of the economy. Some right-wing political tendencies accept the maxim that the state should do what's possible to help the economy ('jumpstarting the economy' argument). By that maxim it would mean the Fed should not raise interest rates. Austrian economics, for example, postulates that interest rates are the price of money. An entity like the Fed keeping them deliberately and artificially low distorts the whole of the economy because it changes prices. Another example is that many sectors of the economy demand some sort of subsidy. Sectors traditionally associated with right-wing politics profit from subsidies, for example, defense industry or agriculture. Austrian economics is skeptical of all forms of subsidies because they distort the individual, subjective calculations of utility and cost.

5. The appropriateness of reading a given theory can be achieved by applying Davidson's principle of charity: the basic problem that radical interpretation must address is that one cannot assign meanings to a speaker's utterances without knowing what the speaker believes, while one cannot identify beliefs without knowing what the speaker's utterances mean. It seems that we must provide both a theory of belief and a theory of meaning at one and the same time. Davidson claims that the way to achieve this is through the application of the so-called 'principle of charity' (Davidson has also referred to it as the principle of 'rational accommodation'), a version of which is also to be found in Quine. In Davidson's work this principle, which admits to various formulations and cannot be rendered in any completely precise form, often appears in terms of the injunction to optimize agreement between ourselves and those we interpret, that is, it counsels us to interpret speakers as holding true beliefs (true by our lights at least) wherever it is plausible to do (Davidson 1973). In the case of this book, it evaluates these authors and their theories in the same background they have been developed.

6. Besides these objections grounded in the institutional view of markets, there are many other ways to challenge the market as optimal equilibrium view. Just take a look at the assumptions that theory has to make in order to work: (a) a set of perfectly competitive markets exists for inputs and outputs; (b) each market has an equilibrium price; (c) equilibrium prices clear the markets; (d) zero transaction costs; (e) perfect knowledge; (f) no transportation costs; (g) the Law of One Price - each good and input obeys this law, which is that the good or input is homogeneous and sells for the same price to everyone in all markets; (h) all consumers are rational price takers both as buyers of goods and sellers of inputs (for example, labor). Each market has a very large number of utility-maximizing consumers for any one good or input; (i) all firms are rational price takers in both input and output markets. Each market has a very large number of profit-maximizing firms producing each homogeneous good or input.

7. Ockham's razor, or the law of briefness, was developed by the fourteenth-century Franciscan friar William of Ockham (1285-1347). Its original formulation was in Latin and can be translated as 'More things should not be used than are necessary.' Often, the razor is understood as a common sense principle saying that the simplest explanation is usually the right one. Ockham, however, was trying to formulate a scientific principle for settling the question of who bears the burden of proof, for example, when claiming that Nature has a Will of its own, or a stone flies because it wants to fly. The razor tells us that if I claim that the stone flies because it wants to fly, it is my responsibility to prove it wanting to fly. If I also claim that the stone flies because I threw it, I would have to prove that too. The simplest proof, then, is the more adequate. Ockham himself also championed other causes like the freedom of the individual, the unconditionality of private property or the privilege of intention over reason. Because of his rather revolutionary thought, he was excommunicated from the Catholic Church (Keele 2010). 
8. It is a matter for historians to say which was the first shared entrepreneurship company in history. Some claim it was the Banco di San Giorgio founded in 1407 in Genoa; others say it was the Vereenigde Oostindische Compagnie (Dutch East India Company) founded in 1602.

9. The shop in shop retail concept is where a brand owner or retailer takes space in another retailer's store and fits it out to provide selling space dedicated to that secondary company's products. Rack jobbing occurs when a wholesaler provides racks of merchandise for retail locations and the wholesaler and the retailer split the profits obtained from sales between the two parties. Convenience stores are often made up of various rack jobbers from large and small wholesalers. Contracted manufacturing is the case when the production of goods by one firm is under the label or brand of another firm. Contract manufacturers provide such a service to several (even competing) firms based on their own or the customers' designs, formulas and/or specifications. 